\title{
Essentials for aerosol delivery to term and pre-term infants
}

\author{
Andrew R. Clark \\ Aerogen Pharma Corporation, San Mateo, CA, USA \\ Correspondence to: Andrew R. Clark. Aerogen Pharma Corporation, Suite 360, 1660 S. Amphlett Blvd, San Mateo, CA 94402, USA. \\ Email: aclark@aerogenpharma.com.
}

\begin{abstract}
Effectively delivering pharmaceutical aerosols to the lungs of preterm and term infants represents a considerable technical challenge. Small infants are obligatory nose breathers, they have small airways, low tidal volumes and rapid respiration rates. It is ethically unacceptable to investigate aerosol deposition in vivo in newborns due to ethical concerns about the radiation exposure involved in imaging studies and drug delivery and blood draws in pharmacokinetics studies. The purpose of the work reported in this article was thus to report the use of modeling to develop an understanding of the regional deposition of aerosols in neonates and to build a theoretical basis for choosing an optimum aerosol size to maximize delivery and minimize variability. Recent data on aerosol deposition in the nasal airways of newborn term and preterm infants was coupled to an established, scalable, lung deposition model to investigate the effects of age, aerosol size and ventilation on regional airway deposition. In the term newborn infant lung deposition ranged from 25\% to $35 \%$ depending on Geometric Standard Deviations (GSDs). Intrasubject variability was minimized for aerosols with larger GSD. However, mean lung deposition is reduced with increasing GSD. A compromise between maximum lung deposition and increased intersubject variability appears to be in the region of GSDs of 1.75. In the 30-week GA preterm infant lung deposition is slightly higher than in the term infant despite smaller airways and lower tidal volumes. This is likely due to the lower inhaled flow rates that are concomitant with lower lung volumes. Finally, when aerosol delivery is directly to the trachea, as it would be if delivered via an endotracheal tube there is a monotonic increase in lung deposition with increasing aerosol size with peripheral deposition peaking at 2 to $3 \mu \mathrm{m}$. However, practical limitations of aerosol transport through endotracheal tubes, limiting delivered aerosol size, likely caps lung deposition at around $30 \%$ to $30 \%$ of the delivered dose.
\end{abstract}

Keywords: Aerosol; deposition; term infants; preterm infants

Submitted Nov 03, 2020. Accepted for publication Jan 29, 2021.

doi: $10.21037 / \mathrm{atm}-20-7265$

View this article at: http://dx.doi.org/10.21037/atm-20-7265

\section{Introduction}

Effectively delivering aerosols to the lungs of preterm and term infants represents one of the last great challenges in pharmaceutical aerosol science. Small infants are obligatory nose breathers, they have small airways, low tidal volumes and rapid respiratory rates (1). In general, when respiratory support is needed, nasal CPAP is used unless mechanical ventilation is indicated. Aerosol delivery to the lungs via the nose during nasal CPAP is technically demanding. The small dimensions of the nasal passages represent a considerable barrier to aerosol penetration into the lower airways and "fine" aerosols are required in order to avoid inertial impaction (2). Once aerosol has penetrated beyond the nose deposition in the lung the challenge becomes rapid respiratory rates resulting in short residence times that do not allow enough time for these "fine" aerosols to sediment and deposit (2). Thus, and to some extent similar to adults inhaling aerosols, there is an optimum aerosol size which is small enough to penetrate the lung, but large enough to sediment and deposit in it.

Further, the intersubject variability in nasal airway 
Table 1 Sources and description of models used to generate the nasal deposition data summary presented in Figure 1

\begin{tabular}{lccc}
\hline Publication & $\begin{array}{c}\text { Model } \\
\text { designation }\end{array}$ & Model age range & $\begin{array}{c}\text { Number of } \\
\text { models }\end{array}$ \\
\hline Tavernini et al. (5) & - & 1 to 79 days & 8 \\
Janssens et al. (11) & SAINT & 9 months & 1 \\
$\begin{array}{l}\text { Minocchieri et al. } \\
\text { (12) }\end{array}$ & PrINT & $\begin{array}{c}28 \text { weeks } \\
\text { Gestational Age }\end{array}$ & 1 \\
Clark et al. (7) & & 4 months & 1 \\
& & 28 weeks & 1 \\
ICRP (9) & Gestational Age \\
\hline
\end{tabular}

dimensions, and the impact this has on nasal deposition, is well documented in adults, children and newborns (3-5). Thus, not only is there an optimum size resulting in maximum lung deposition in an individual, but there is also an optimum aerosol size that minimizes intersubject variability. These optimum sizes may or may not be the same and it may be necessary to sacrifice higher deposition in some individuals to ensure reasonable deposition in others. This makes it a challenging exercise to choose the appropriate aerosol size for this group of tiny patients.

In addition, it is impossible to directly investigate aerosol deposition in newborns using conventional in vivo techniques due to ethical concerns about the radiation exposure involved in imaging studies and drug delivery and blood draws in pharmacokinetics studies (6).

The purpose of the work reported in this article was to use modeling to develop an understanding of regional deposition in neonates and, by way of sensitivity analysis, to estimate the effects of age, lung characteristics and inhaled flow rates on the optimum aerosol size. The method chosen was to integrate recent data from publications on deposition in neonatal nasal casts (7) with a numerical deposition model based and an algebraic formulation developed by Rudolf et al. (8). This algebraic model was based on data gathered and summarized by the Task Group on Lung Dynamics (9). The model was chosen specifically because it was developed to represent normal tidal breathing of a uniform aerosol concentration, as would be experienced when inhaling droplets from nebulizers and the later part of the model allows for scaling constants that represent the relative sizes of the major airway compartment across age groups.

\section{Methods}

The deposition model employed the data summarized by Clark et al. (7) describing nasal deposition in newborns and premature infants coupled to a modified version of the algebraic deposition model described by Rudolf et al. $(8,10)$. The variability in nasal deposition was characterized by minimum, mean and maximum deposition efficiency curves and this was coupled to the mean deposition functions from the algebraic model. This approach was taken for two reason; Firstly, nasal variability is much higher than airway variability and therefore has a much bigger impact on deposition and secondly because it was felt that the amount and nature of the nasal deposition data did not readily facilitate reliable estimates of $95 \%$ confidence limits. Thus, the two approaches to assessing variability, minimum maximum for nasal deposition and $95 \%$ confidence limits for the algebraic model are not compatible.

\section{Nasal deposition}

The source of the data and age of the infants on which the nasal models are based are described in Table 1. The nasal deposition data are presented in Figure 1. Although this collection of data does not strictly represent only newborn term or preterm infants it should be noted that data from specific models of preterm infants fall well within the data spread and examination across multiple age ranges from preterm to adults (3-5) shows large intersubject variability with only a small trend with age. It was therefore felt that, for the purposes of this initial theoretical investigation using this data set without any attempts to extrapolate to preterm infants was acceptable. Indeed, because of the variability it is difficult to identify a valid basis for such an extrapolation. Tavernini and colleagues (5) devoted considerable analytical effort to finding a function which explained (minimized) intersubject variability in their nasal models. They finally settled on a function involving Stokes and Reynolds numbers. However, the variables used to calculate these dimensionless groups, while readily obtained from models, are not available in live preterm infants. The only variables that can be practically controlled and/or measured during nasal aerosol delivery to neonates are particle size, $\mathrm{d}$, and flow rate, Q. Hence, the representation of data set relating nasal deposition to the impaction parameter, $\mathrm{d}^{2} \mathrm{Q}$, as the dependent variable was used for this modeling exercise, Figure 1. It should be noted, although not obvious from the figure, that not only are there differences between 


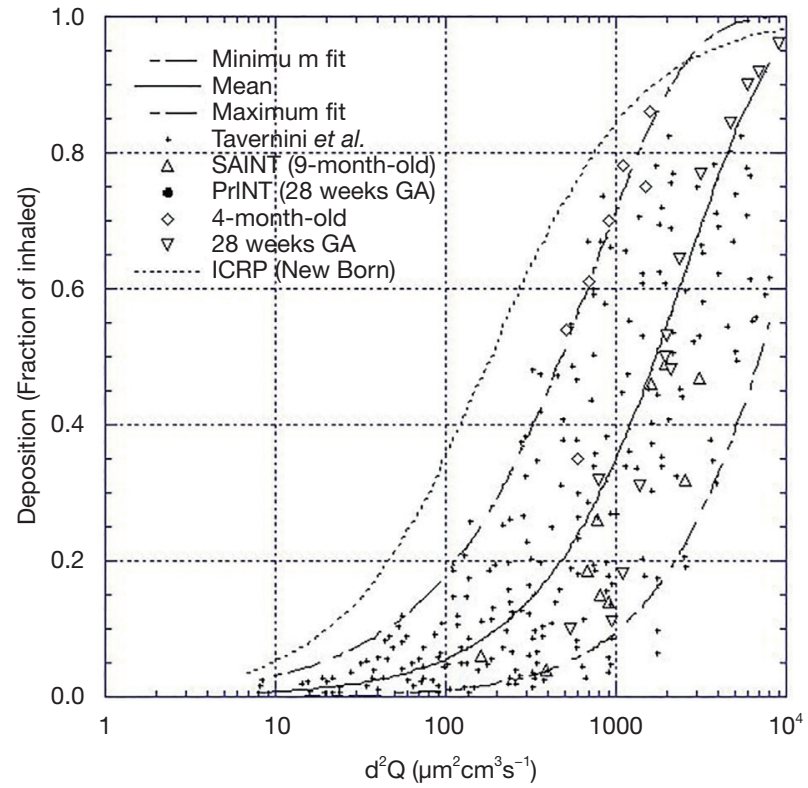

Figure 1 Summary of available nasal deposition data and fitted minimum (dashed line right), mean (solid line) and maximum (dashed line left) deposition curves. The bulk of the data (8 nasal models) are from Tavernini et al. (5), the SAINT data is from Storey-Bishoff et al. (11), the PrINT data is calculated from Minocchieri et al. (12) and the 4-month and 28 weeks old model data is from Clark et al. (7). Also shown is the original ICRP model for nasal deposition in newborns (9).

individual nasal models but also for a given model tested under different flow conditions.

Data relating nasal deposition efficiency to $d^{2} Q$ from the infant nasal models were fitted (minimum, mean and maximum) using a hyperbolic function of the form;

$$
\eta=100 \times\left(1-\exp \left(-a\left(d^{2} Q\right)^{p}\right)\right.
$$

Where a and $\mathrm{P}$ are fitting constants.

Equation [1], with the appropriate fitting constants representing the maximum, mean and minimum deposition efficiency curves are shown in Figure 1. The mean curve was fitted using a least squares fitting routine, the minimum and maximum curves were fitted by eye. The fitted curves were used as a replacement for the nasal deposition function employed in the published algebraic model.

For completeness also shown in Figure 1 is the curve generated using the nasal deposition equation [2] used in the published model that was originally adopted by the International Commission on Radiological Protection using their scaling constants for a newborn infant (9).

$$
\eta=1-\left(2.1 \times 10^{-4} \times d^{2} Q S F_{T}^{3}+1\right)^{-1}
$$

Where $\mathrm{SF}_{\mathrm{T}}$ is a scaling factor based on the ratio of trachea diameters for adults to newborns and is used to scale adult nasal deposition data to newborns. Given that no data existed to validate this use of $\mathrm{SF}_{\mathrm{T}}$ at the time of the model's development, this function was justified based on limited work performed by Zhou (13) and Swift (14). Since this equation and scaling correction obviously overestimates nasal deposition compared to the nasal models employed in more recent publications it was not considered further during this modeling investigation.

\section{Lung deposition}

With the substitution of the fitted nasal deposition function described above (Eq. [1]), the algebraic model of Rudolf et al. $(8,10)$ was used in its published form. The model is described in detail elsewhere (8). Briefly, deposition in each airway compartment is calculated using two empirical equations, one representing inertial deposition and the other diffusional deposition. Total deposition is then calculated as the root mean square of the two components. In addition to particle size the model requires a set of physiological variables and age-related scaling factors. In its original published form these variables are given for adults, children and newborn (term) infants. The variables for newborn infants are presented in Table 2.

\section{Calculations}

The algebraic model with the above nasal equations included was implemented using an Excel spreadsheet (Microsoft, Office 365). Fractionated log-normal particle distributions we generated for various Mass Median Aerodynamic Diameters (MMADs) and GSDs using a geometric size band multiplier. The regional deposition of the geometrically weighted mean for each size band was calculated using the algebraic deposition model. Total deposition in each region of the airways, nose, lung (conducting and peripheral regions), and exhaled fractions were then calculated by summation across the entire size distribution. The size distribution of the aerosol depositing in each airway region was also calculated. The calculations flow is illustrated in Figure 2. The detailed equations can be found in Rudolf et al. (8). 
Table 2 ICRP and modeling parameters for newborns and a 30 -week gestational age premature infant

\begin{tabular}{lcc}
\hline Age range & Newborn $^{\#}$ & 30 weeks GA ${ }^{\$, \&}$ \\
\hline Physiological parameters & & \\
Inhaled flow rate $(\mathrm{Q})$ & $65 \mathrm{~mL} / \mathrm{s}$ & $20 \mathrm{~mL} / \mathrm{s} / \mathrm{kg}$ \\
Inhaled volume $\left(\mathrm{V}_{\mathrm{t}}\right)$ & $39 \mathrm{~mL}$ & $5.685 \mathrm{~mL} / \mathrm{kg}$ \\
Forced residual capacity (FRC) & $110 \mathrm{~mL}$ & $37 \mathrm{~mL}$ \\
Extra Thoracic volume $\left(\mathrm{V}_{\mathrm{E}}\right)$ & $2 \mathrm{~mL}$ & $0.6 \mathrm{~mL}$ \\
Tracheobronchial volume $\left(\mathrm{V}_{\mathrm{Bo}}\right)$ & $4 \mathrm{~mL}$ & $1.25 \mathrm{~mL}$ \\
Bronchiolar volume $\left(\mathrm{V}_{\mathrm{bo}}\right)$ & $7 \mathrm{~mL}$ & $2.2 \mathrm{~mL}$ \\
Scaling factors & & \\
Trachea (SFT) & & 3.61 \\
Bronchial (SFB) & 2.989 & 1.84 \\
Alveolar (SFA) & 1.674 & 2.80 \\
\hline
\end{tabular}

\#, data obtained form $(8,9) ;{ }^{\$}$, physiological parameters derived from (15); ${ }^{\&}$, inhaled volumes and flow rates obtained from (16);

@ , scaling factors calculated using diameters of airway groups determined from autopsies of premature infants (17).

Base calculations were performed using the published ICRP parameters for newborns and the minimum, mean and maximum nasal deposition functions derived from the data presented in Figure 1. A range of particle sizes, 1.25 to $9.0 \mu \mathrm{m}$ MMAD, and GSDs, 1, 1.75, 2.5 were investigated.

In addition, deposition in a 30-week Gestational Age premature infant was investigated. Scaling for the trachea, central and peripheral zone, as required by the algebraic model, were calculated using autopsy data (17) (Table 2). Sensitivity analysis around the based case 30-week GA infant was performed by varying lung volumes in proportion to inhaled flowrate and then by varying inhaled flow rates with a fixed lung volume.

Finally, the model was adapted to investigate aerosol delivery directly into the trachea of newborn infants by assuming no nasal filtering. This is somewhat equivalent to delivery via an endotracheal tube during mechanical ventilation, but not attempt was made to model flows through an ET tube. Calculations were performed for a term and 30-week GA infant.

\section{Results}

Figure $3 A, B, C$ present regional deposition and exhaled aerosol as percentage of the inhaled dose for aerosols of varying MMAD and a GSD of 1.75. Three curves are presented for each region representing the minimum, mean and maximum nasal deposition as determined from the nasal cast data. As would be expected at large MMADs nasal capture limits aerosol penetration into the lung and at small MMADs lung retention is limited by exhalation. For a newborn conforming to the breathing parameters and scaling factors described in Table 1 mean lung deposition reaches $30 \%$ at an MMAD of $3 \mu \mathrm{m}$. However, the range of deposition, maximum to minimum nasal retention, varies from $10 \%$ to $45 \%$, i.e., a factor of over 4 . Of note, as would be expected, the median size at which peak lung deposition occurs varies inversely with degree of nasal retention and increases as nasal retention decreases.

Figure $4 A, B, C$ present total lung deposition as a function of GSD for aerosols of various MMADs. Increasing GSD flattens the dependency of deposition upon particle size and reduces peak lung deposition, while at the same time decreasing variability. Mean peak lung deposition decreases from $37 \%$ to $24 \%$ and variability (ratio of highest to lowest), decreases by $20 \%$ (from 3.6 to 2.6 ) as GSD increases from 1.0 to 2.5. Indicating, as would be expected, that deposition of mono disperse aerosols is more sensitive to variation in intersubject airway parameters.

Figure 5 presents the lung deposition data for a 30-week GA premature infant. Figure $5 A$ shows the effect of inhaled flowrate assuming lung volumes are scaled in proportion to inhaled flowrate. Figure $5 B$ shows the effect of inhaled flow rate assuming fixed airway volumes. In either case increasing inhaled flow rates results in lower lung deposition, in the case of Figure $5 \mathrm{~A}$ that is despite an increase in lung volumes. It should also be noted that rather than a reducing lung deposition, compared to a term newborn, lung deposition is slightly enhanced. This slight increase is well within the maximum variability generated by variations in nasal deposition exemplified in Figure 3.

Figure 6 presents the results of modelling aerosol delivery directly into the trachea as would be the case when aerosol delivery is via an endotracheal tube during mechanical ventilation. (Note: no attempt was made to model any jet like flow that might be induced at the exit of the ETT). Figure $6 A$ presents data for a newborn and Figure $6 B$ for an appropriately scaled 30-week GA premature infant. Scaling constants and inhalation parameters were as presented in Table 1 and indicated in the figures. In this case there is no filtering in the nose and the only factor limiting lung deposition is exhalation. Hence, lung deposition increases 
Input Parameters

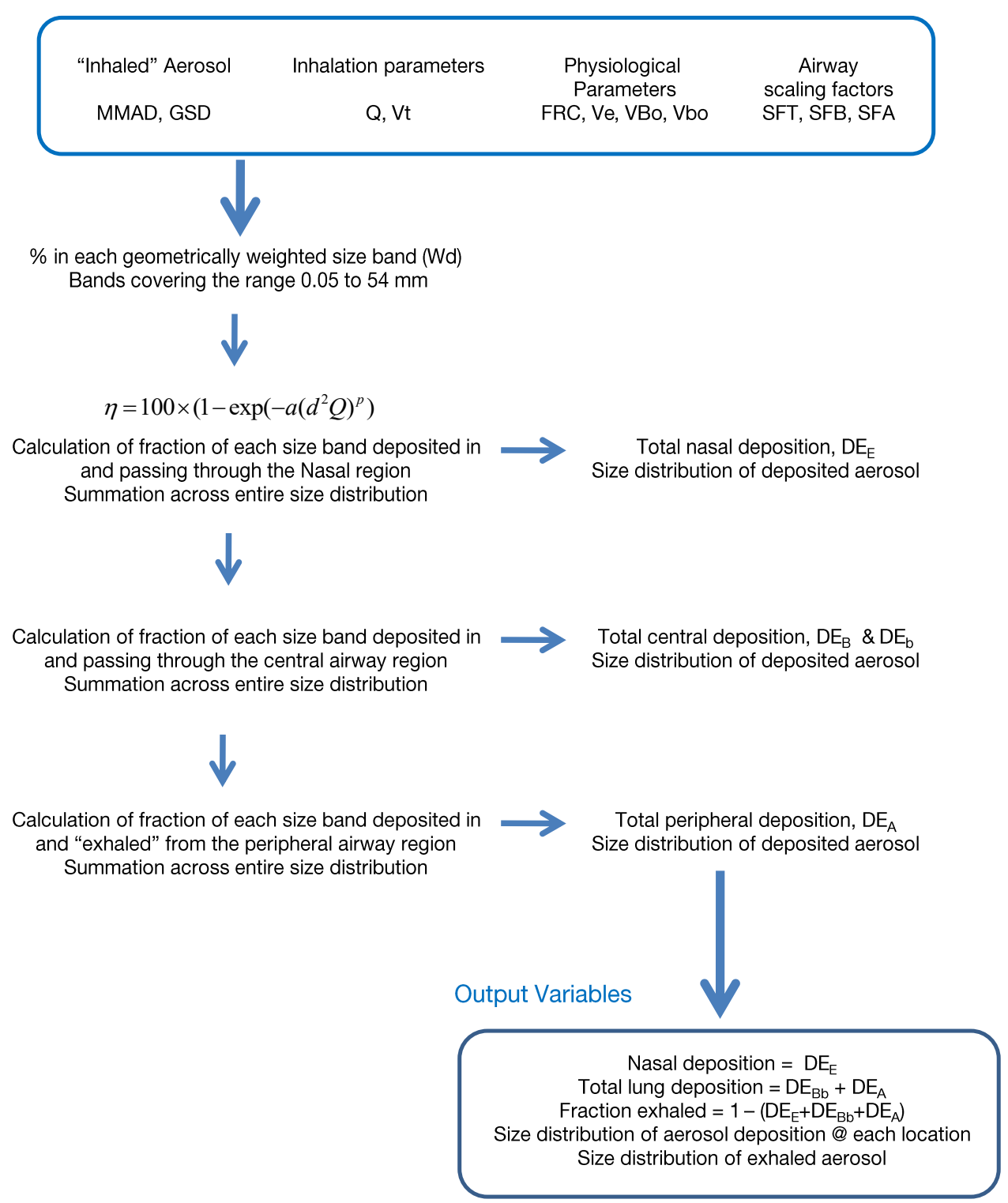

Figure 2 Calculation flow for deposition modeling illustrating input parameters and output variables. The model was implemented in an Excel Spreadsheet (Microsoft, Version 2020).

monotonically with increasing aerosol size. However, peripheral deposition does show a maximum which is controlled by the competing mechanisms of upper airway "filtering" and exhalation. Peripheral deposition shows a functional similarity to total lung deposition for nasal inhalation and peak deposition, of $33 \%$, occurs at a similar MMAD. Peripheral deposition is slightly enhanced in the younger age infant.

\section{Conclusions}

We report the results of a modeling exercise investigating regional aerosol deposition in term and preterm infants. The method used combined recently published nasal deposition data, obtained from nasal models, with an established lung deposition model that allowed airway scaling for age based on airway dimensions. While the data gathered from nasal models is limited, both by age and 

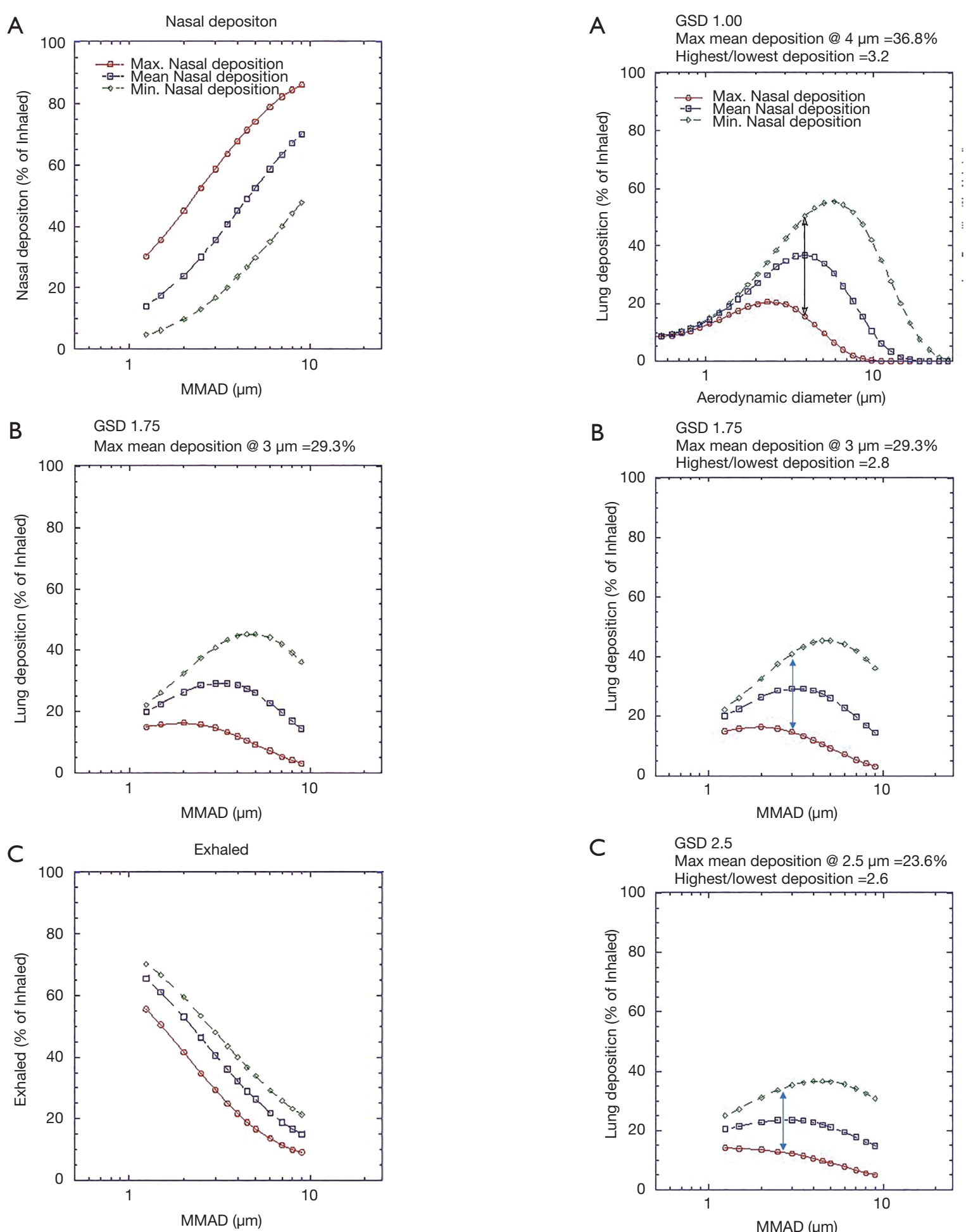

Figure 3 (A) Nasal deposition, (B) total lung deposition and (C) exhaled percentage in a term infant as a function of Mass Median Aerodynamic Diameter for an aerosol with GSD of 1.75 for nasal breathing in a newborn infant. Each figure shows the result of the minimum, mean and maximum nasal filtering.

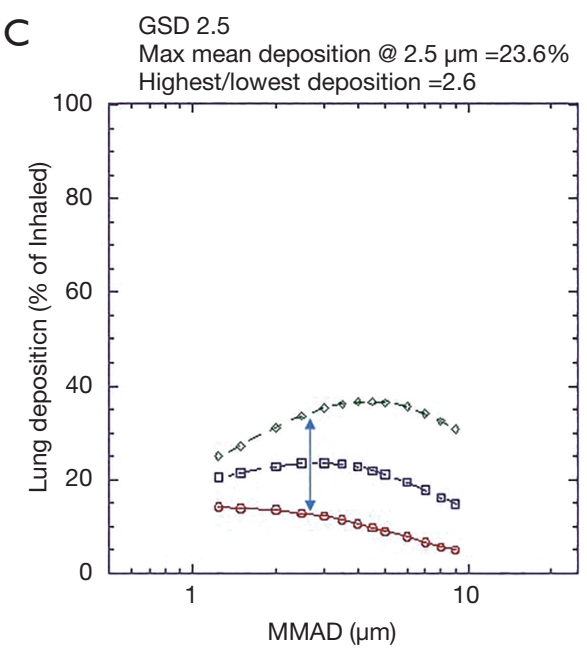

Figure 4 Total lung deposition as a function of aerodynamic diameter in a term infant for (A) a monodispersed aerosol (GSD 1.0) and Mass Median Aerodynamic Diameter for (B) GSD 1.75 and (C) GSD 2.5. With variance shown as ratio of highest/lowest deposition. 

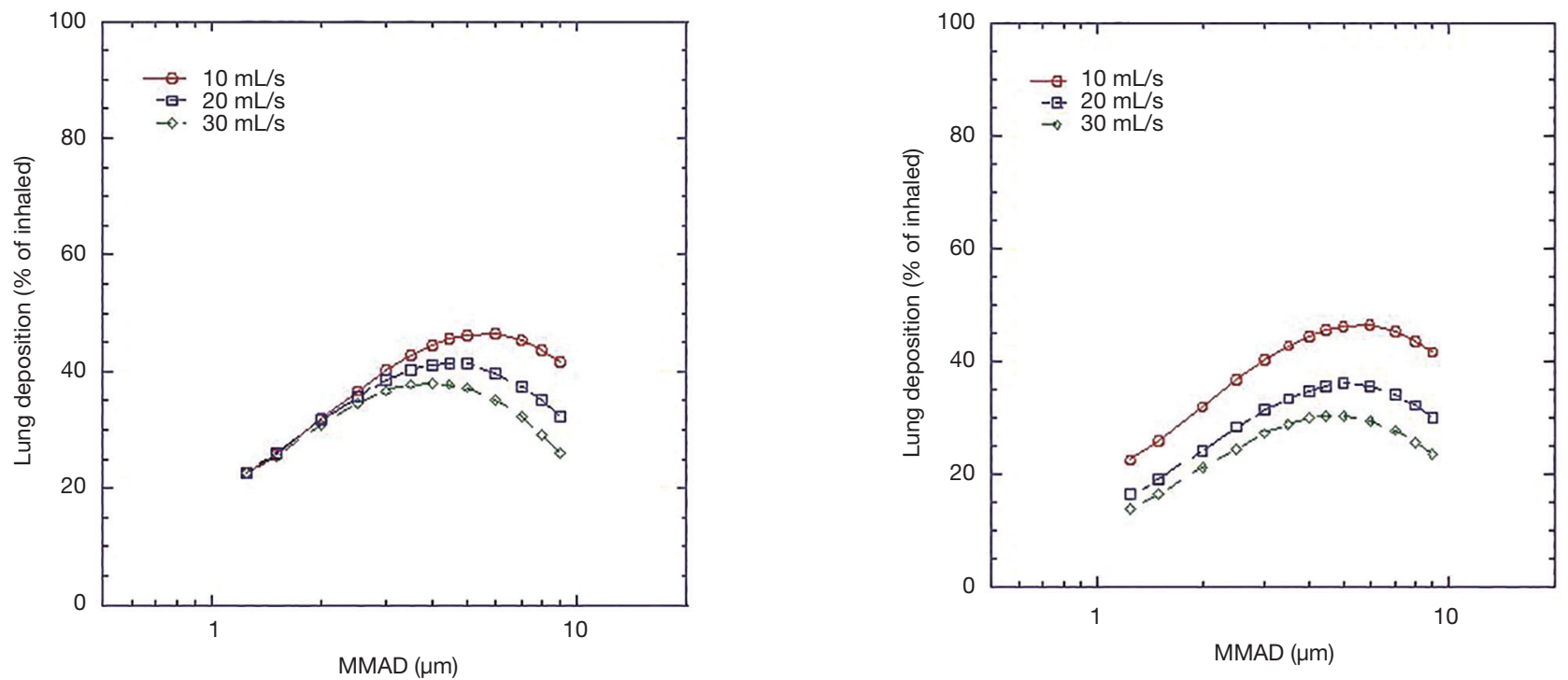

\begin{tabular}{|l|c|c|c|}
\hline Inhaled flow rate $(\mathrm{Q})$ & $10 \mathrm{~mL} / \mathrm{s}$ & $20 \mathrm{~mL} / \mathrm{s}$ & $30 \mathrm{~mL} / \mathrm{s}$ \\
\hline Inhaled volume $\left(\mathrm{V}_{\mathrm{t}}\right)$ & $9.8 \mathrm{~mL}$ & $5.85 \mathrm{~mL}$ & 18 \\
\hline Forced residual capacity $(\mathrm{FRC})$ & $27.5 \mathrm{~mL}$ & $37 \mathrm{~mL}$ & 51 \\
\hline Extra thoracic volume $\left(\mathrm{V}_{\mathrm{t}}\right)$ & $0.5 \mathrm{~mL}$ & $0.6 \mathrm{~mL}$ & 0.9 \\
\hline Tracheobronchial volume $\left(\mathrm{V}_{\mathrm{bc}}\right)$ & $1 \mathrm{~mL}$ & $1.25 \mathrm{~mL}$ & 1.8 \\
\hline Bronchiolar volume $\left(\mathrm{V}_{\mathrm{bc}}\right)$ & $1.75 \mathrm{~mL}$ & $2.2 \mathrm{~mL}$ & 3.2 \\
\hline Trachea $(\mathrm{SFT})$ & \multicolumn{3}{|c|}{3.61} \\
\hline Bronchial $(\mathrm{SFB})$ & \multicolumn{3}{|c|}{1.84} \\
\hline Alveolar $(\mathrm{SFA})$ & 2.80 \\
\hline
\end{tabular}

\begin{tabular}{|c|c|c|c|}
\hline Inhaled flow rate $(\mathrm{Q})$ & $10 \mathrm{~mL} / \mathrm{s}$ & $20 \mathrm{~mL} / \mathrm{s}$ & $30 \mathrm{~mL} / \mathrm{s}$ \\
\hline Inhaled volume $\left(\mathrm{V}_{\mathrm{t}}\right)$ & \multicolumn{3}{|c|}{$5.85 \mathrm{~mL}$} \\
\hline Forced residual capacity (FRC) & \multicolumn{3}{|c|}{$37 \mathrm{~mL}$} \\
\hline Extra thoracic volume $\left(\mathrm{V}_{\mathrm{t}}\right)$ & \multicolumn{3}{|c|}{$0.6 \mathrm{~mL}$} \\
\hline Tracheobronchial volume $\left(\mathrm{V}_{\mathrm{bc}}\right)$ & \multicolumn{3}{|c|}{$1.25 \mathrm{~mL}$} \\
\hline Bronchiolar volume $\left(\mathrm{V}_{\mathrm{bc}}\right)$ & \multicolumn{3}{|c|}{$2.2 \mathrm{~mL}$} \\
\hline Trachea (SFT) & \multicolumn{3}{|c|}{3.61} \\
\hline Bronchial (SFB) & \multicolumn{3}{|c|}{1.84} \\
\hline Alveolar (SFA) & \multicolumn{3}{|c|}{2.80} \\
\hline
\end{tabular}

Figure 5 A comparison of total lung deposition for a newborn term infant versus a 30 -week gestational age preterm infant for aerosol with a GSD of 1.75 .

number, it shows high variability both across individuals and within individuals across inhalation parameters. Nasal deposition was therefore modelled as maximum, mean and minimum deposition efficiency using a hyperbolic form utilizing two fitting parameters. Airway dimension, to calculate scaling factors, were obtained from autopsy data and inhalation parameters from published sources. Overall, even though this combined input data set was limited, it was enough to model and estimate the effects of various parameters on regional deposition.

In the newborn term infant lung deposition ranged from $25 \%$ to $35 \%$ depending on GSD. Intrasubject variability was minimized with larger GSDs, but lung deposition was reduced. This illustrates the importance of the width of the aerosol size distribution, too narrow and intrasubject variability is high to broad on intrasubject variability is low, but so is total lung deposition. A compromise appears to be in the region of GSDs of 1.75 . In the 30-week GA preterm infant lung deposition was slightly higher than in the term infant despite small airways and lower tidal volumes. This is likely due to the lower inhaled flow rates that are concomitant with lower lung volumes as illustrated by the relationship between inhaled flow rate for fixed lung volumes exemplified in Figure $6 B$.

The data on regional deposition during mechanical ventilation shows a monotonic decay in total lung deposition as aerosol size is reduced while exhibiting a similar profile in peripheral deposition to total lung deposition in nasal delivery. The reason for this is illustrated in Figure 7. There is close similarity between nasal filtering and central airway filtering of the inhaled aerosol which result in peak peripheral deposition occurring at similar sizes to peak lung deposition from nasal breathing. It should be noted however, as stated above, that any jetting at the base of an ET tube has been ignored for the purposes of modeling. It should also be noted that the ET tube itself acts as an inertial filter and there are reports that aerosols with MMADs much large than $2 \mathrm{~m}$ are filtered out prior to entering the airways. Liu et al. (18) in an in vitro study investigating aerosol delivery via mechanical ventilation 

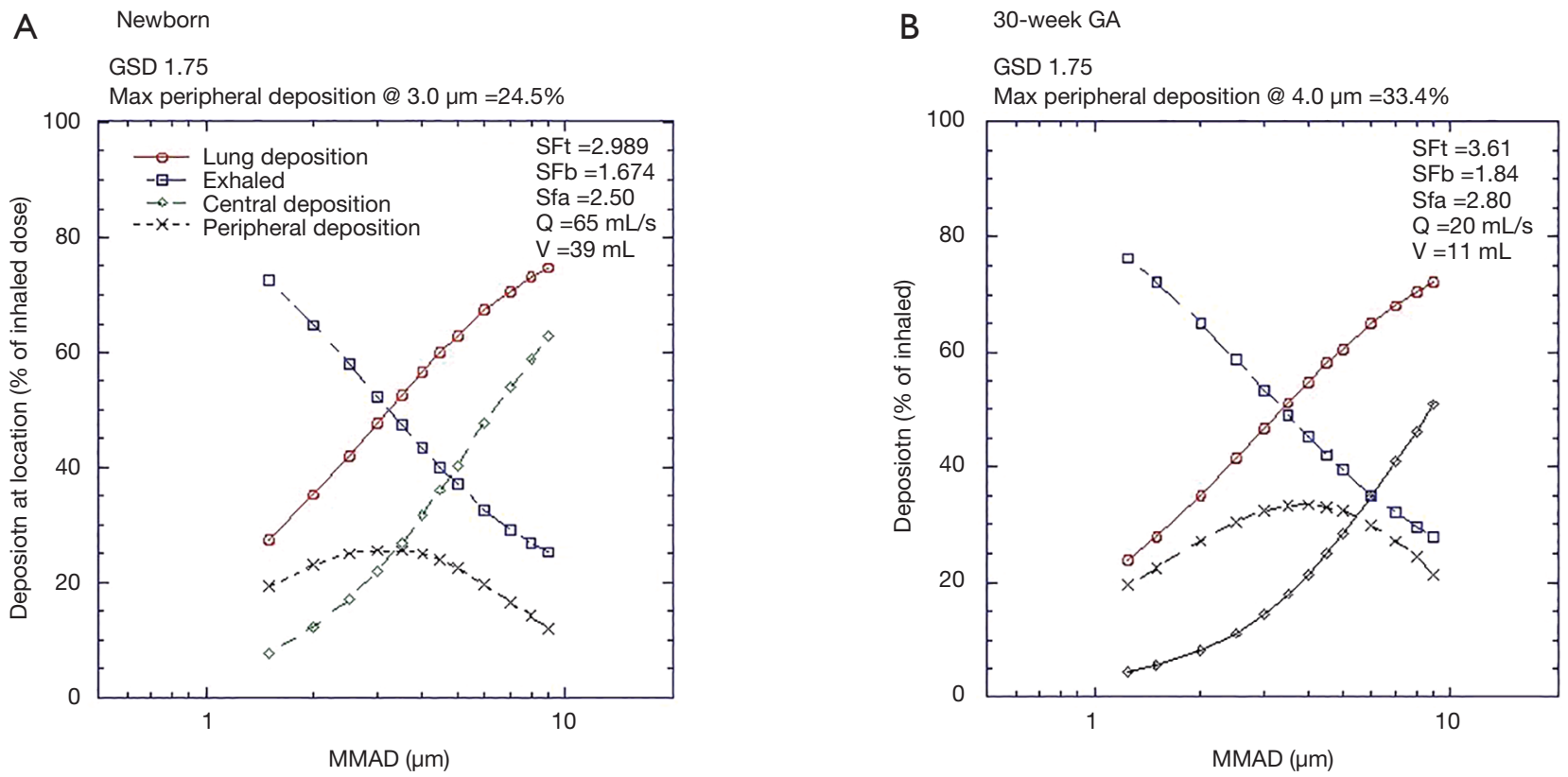

Figure 6 Regional deposition of aerosol with a GSD of 1.75 in intubated infants. Aerosol is assumed to be delivered directly distal to the trachea, i.e., bypassing the nasal passages and nasal filtering. (A) Newborn term infant, (B) 30-week gestational age preterm infant.

showed that regardless of the nebulizer used to generate the primary aerosol, or position of the nebulizer, aerosols exiting the ET tube had MMADs smaller than $2.5 \mu \mathrm{m}$. Similarly, Dugernier and colleagues showed in a study comparing aerosol delivery using two ventilation modes (pressure and volume control) that the aerosols delivered distal to the ET tube were 2.1 and $1.9 \mu \mathrm{m}$ MMAD respectively (19). Thus, even though these studies were performed using adult ventilators and ETT sizes, it is unlikely aerosols with MMADs greater than $2 \mu \mathrm{m}$ are would reach a neonate's lung and the increase in lung deposition seen with larger MMADs is not relevant to practical therapy. Coincidently, 2 to $2.5 \mu \mathrm{m}$ MMAD is close to the predicted maximum peripheral deposition within the lung as shown in Figure 5 . There are less conventional techniques that could take advantage of increasing lung deposition with increase size. For example, producing large droplets from a nebulizing catheter placed though the ET tube and positioned in the trachea as proposed by Aramendia and colleagues (20). However, while likely enhancing lung deposition this would result in high central deposition and has several practical disadvantages, such as temporarily obstructing the trachea and interfering with ventilation.

Finally, the model used in this investigation assumes a uniform aerosol concentration during each breath and presents an estimate of the regional deposition as fraction of the inhaled aerosol. Because of the anatomical dead space (extra thoracic volume) in the airways a fraction of the aerosol inspired near the end of inspiration will not penetrate beyond the nose and into the lower airway and will be exhaled. Delivering aerosol early and for a portion of inspiration allow chase air to clear aerosol from the dead space and transport that part of the aerosol deeper into the airway enhancing lung deposition beyond the values presented here. In the newborn the extra thoracic volume is estimated as $4 \mathrm{~mL}$ and the tidal volume at $39 \mathrm{~mL}$ (8). In preterm infants the volumes are unclear, with estimates of nasal volumes of $1.2 \mathrm{~mL}$ for the 28-week preterm PrINT model (12). With tidal volumes as low as 5 to $7 \mathrm{~mL} / \mathrm{kg}$ in preterm infants $(21,22)$ the anatomical dead space can represent $10 \%$ to $20 \%$ of the tidal volume and for maximum efficiency aerosol delivery should thus be restricted to the first $80 \%$ of each breath. Further inspiratory/expiratory ratios can be as high as 1:4 in small infants and obviously continuous nebulization would result in a large drop in overall delivery efficiency as up to $80 \%$ of the generated aerosol would be generated during exhalation and would be wasted.

It can be concluded from this modeling that it should be possible to deliver medical aerosols to neonates via 


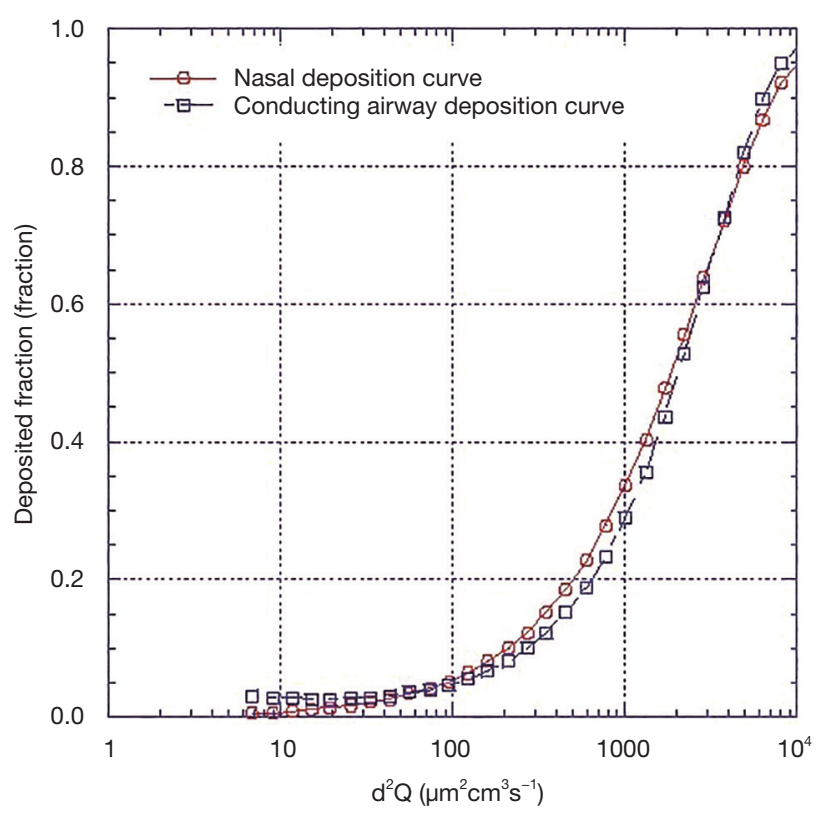

Figure 7 A comparison of Nasal filtering (mean curve form Figure 1) with conducting airway filtering efficiency versus $\mathrm{d}^{2} \mathrm{Q}$ illustrating the similarity of the two and explaining the peak in conducting airway deposition seen in Figure 6.

nasal CPAP or ventilator with reasonable efficiency and reproducibility provided that; the MMAD is around 2.5 to $3 \mu \mathrm{m}$, the GSDs of the inspired aerosols are moderate, 1.5 to 2.0 , delivery is breath synchronized and aerosol generation/delivery only takes place in the first $80 \%$ of the breath.

\section{Acknowledgments}

The author would like to thank Jim Fink for his support and reviewing the manuscript.

Funding: None.

\section{Footnote}

Provenance and Peer Review: This article was commissioned by the Guest Editors (Dr. James B. Fink and Dr. Zhe Luo) for the series "Medical Aerosol in Acute and Critical Care" published in Annals of Translational Medicine. The article has undergone external peer review.

Conflicts of Interest: The author has completed the ICMJE uniform disclosure form (available at http://dx.doi. org/10.21037/atm-20-7265). The series "Medical Aerosol in
Acute and Critical Care" was commissioned by the editorial office without any funding or sponsorship. The author has no other conflicts of interest to declare.

Ethical Statement: The author is accountable for all aspects of the work in ensuring that question related to the accuracy or integrity of any part of the work are appropriately investigated and resolved.

Open Access Statement: This is an Open Access article distributed in accordance with the Creative Commons Attribution-NonCommercial-NoDerivs 4.0 International License (CC BY-NC-ND 4.0), which permits the noncommercial replication and distribution of the article with the strict proviso that no changes or edits are made and the original work is properly cited (including links to both the formal publication through the relevant DOI and the license). See: https://creativecommons.org/licenses/by-nc-nd/4.0/.

\section{References}

1. MacLoughlin R, Telfer C, Clark A, et al. Aerosol: A Novel Vehicle for Pharmacotherapy in Neonates. Curr Pharm Des 2017;23:5928-34.

2. Finlay WH, Martin AR. Recent advances in predictive understanding of respiratory tract deposition. J Aerosol Med Pulm Drug Deliv 2008;21:189-206.

3. Hounam RF, Black A, Walsh M. Deposition of aerosol particles in the nasopharyngeal region of the human respiratory tract. Nature 1969;221:1254-5.

4. Storey-Bishoff J, Noga M, Finlay WH. Deposition of micrometer-sized particles in infant nasal airway replicas. J Aerosol Sci 2008;39:1055-65.

5. Tavernini S, Church TK, Lewis DA, et al. Deposition of micrometer-sized particles in neonatal nasal airway replicas. Aerosol Science and Tech 2018;52:407-19.

6. Callahan MJ, MacDougall RD, Bixby SD, et al. Ionizing radiation from computed tomography versus anesthesia for magnetic resonance imaging in infants and children: patient safety considerations. Pediatr Radiol 2018;48:21-30.

7. Clark A, McKenna C, MacLoughlin R. Aerosol Delivery in Term and Preterm Infants: The final Frontier. Available online: https://www.researchgate.net/ publication/324921241_Aerosol_Delivery_in_Term_and_ Preterm_Infants_The_Final_Frontier

8. Rudolf G, Kobirch R, Stahlhofen W. Modeling and algebraic formulation of regional deposition in man. J Aerosol Sci 1990;22:S403-6. 
9. James AC, Stahlhofen W, Rudolf G, et al. The respiratory tract deposition model proposed by the ICRP Task Group. 3rd Int workshop on respiratory tract dosimetry, Albuquerque, NM, 1990.

10. Rudolf G, Gebhart J, Heyder J, et al. An empirical formula describing aerosol deposition in man for any particle size. J Aerosol Sci 1986;17:350-5.

11. Janssens HM, Jongste JC, Fokkens WJ, et al. The Sophia anatomical infant nose-throat (SAINT) model: A valuable tool to study aerosol deposition in infants. J Aerosol Med 2001;14:433-41.

12. Minocchieri S, Burren JM, Bachmann MA, et al. Development of the premature infant nose-throat model (PrINT-Model) - an upper airway replica of a premature neonate for the study of aerosol delivery. Pediatr Res 2008;64:141-6.

13. Zhou Y, Guo M, Xi J, et al. Nasal deposition in infants and children. J Aerosol Med Pulm Drug Deliv 2014;27:110-6.

14. Swift D. Age-related scaling for aerosol and vapor deposition in the upper airways of humans. Health Phys 1989;57:293-7.

15. Latzin P, Roth S, Thamrin C, et al. Lung volume, breathing pattern and ventilation inhomogeneity in preterm and term infants. PLoS One 2009;4:e4635.

16. Al-Hathlol K, Idiong N, Kwiatkoshi K. A study of

Cite this article as: Clark AR. Essentials for aerosol delivery to term and pre-term infants. Ann Transl Med 2021;9(7):594. doi: 10.21037/atm-20-7265 breathing pattern and ventilation in newborn infants and adult subjects. Act Paediatr 2000;89:1420-5.

17. Hislop AA, Haworth SG. Airway size and structure in normal fetal and infant lung and the effect of premature delivery and artificial ventilation. Acta Paediatr 2000;89:1420-5.

18. Liu CY, Ko HK, Fink JB, et al. Size distribution of colistin delivery by different type nebulizers and concentration during mechanical ventilation. Pharmaceutics 2019;11:459.

19. Dugernier J, Reychler G, Wittebole Z, et al. Aerosol delivery with two ventilation modes during mechanical ventilation: a randomized study. Ann Intensive Care 2016;6:73.

20. Aramendia I, Fernandez-Gamiz U, Lopez-Arraiza A, et al. Aerosol delivery by inhalation catherer and trachea digitalization. XXXV Congresso annual de la Sociedad Espanola de Ingenieria Biomedica, Bilbao, Nov 2017.

21. Mian Q, Cheung PY, O'Reilly M, et al. Spontaneously breathing preterm infants change tidal volume to improve lung aeration immediately after birth. J Pediatr 2015;167:274-8.

22. Mian Q, Pichler G, Binder C, et al. Tidal volumes in spontaneously breathing preterm infants supported with continuous positive airway pressure. J Pediatr 2014;165:702-6. 